\title{
Survival among pneumonic children: A prospective study of western Odisha
}

\author{
Subash Chandra Majhi ${ }^{1}$, Baikuntha Nath Kashyap,"* \\ ${ }^{\mathbf{1}}$ Associate Professor, ${ }^{\mathbf{2} S e n i o r ~ R e s i d e n t, ~ D e p t . ~ o f ~ P e d i a t r i c s, ~ V I M S A R ~ M e d i c a l ~ C o l l e g e, ~ B u r l a, ~ O d i s h a, ~ I n d i a ~}$
}

*Corresponding Author:

Email: baikunthanath.kashy ap @ gmail.com

\begin{abstract}
Introduction: Pneumonia is still the leading cause of morbidity and mortality of our country, approximately $16 \%$ of deaths among children under 5 vears of age globallv and as per NITI Aavog report 2015: the under-five mortalitv rate (U5MR) of Odisha is 39 and the most common causes of under-five mortality being pneumonia. Many studies have been done on pneumonic children but currently survival analy sis of these children is rare.

Methods: The present observational, analytical, hospital based prospective cohort study was conducted over a period of 12 months in a tertiary hospital of western Odisha. Total 152 children were included in the study after satisfying the predefined inclusion and exclusion criteria and ethical committee approval bv simple consecutive sampling method. CRF was used to record all relevant data of the study participants and SPSS v25 was used for survival analy sis.

Results: Median duration of survival in days of children with severe pneumonia (8.0, 6.60 to 9.39) is not significantly higher than the children with very severe pneumonia (7.0, 4.89 to 9.10$)$ as evidenced by Breslow chi-square $=3.93(1), p=0.057$. There is no overall difference in survival among gender, immunization status, breast feeding status, exposure to smoke, socio economic groups and gestational age as evidenced bv $\mathrm{p}>0.05$.

Conclusion: Disease survival (time to event analysis) is not affected by the severity (severe vs very severe pneumonia) of the illness, which may be due to the fact that late diagnosis and late referral from the peripheral centre. So the skill of the health workers and the health technologies should be strengthened at the primary level.
\end{abstract}

Keywords: Very severe pneumonia, Severe pneumonia, Kaplan meier survival analy sis, Mortality, CRF.

\section{Introduction}

Pneumonia is the inflammation of the parenchyma of lungs which caused $16 \%$ of deaths among children under age 5, by cause globally, 2016. ${ }^{1}$ Although as per a coverage evaluation survey during November 2009 to January 2010 in India commissioned by UNICEF, $82.6 \%$ of children with ARI sought treatment/advice. ${ }^{2}$ As per NITI Aayog report 2015, the under-five mortality rate (U5MR) of Odisha is $39^{3}$ and the most common causes of under-five mortality being pneumonia, diarrhoea, malaria \& measles. So Odisha is also not much behind contributing this under-five mortality due to pneumonia. But the death and the survival of under 5 children due to pneumonia is greatly influenced by access to basic health services and the quality of socio-economic services that are made available to the population. ${ }^{4}$ Many studies have been done on pneumonia but survival analysis in these studies is rare. So this survival analysis study was done with the aims to identify key socio-economic and health-related factors that may be responsible for mortality amongst under-five children having pneumonia. The study further seeks to propose feasible recommendations on the basis of the findings of the study to the health care sectors.

\section{Methods}

The present observational, analytical, hospital based prospective cohort study was conducted over a period of 12 months (April 2017 to March 2018) in VIMSAR Medical College, Burla, Odisha, of India which is a 900 bedded tertiary care hospital of western
Odisha, after getting approval from institutional ethics committee. Inclusion criteria being children between two-months to five-year of age having features of severe and very severe pneumonia and exclusion criteria being children below two-months of age and more than five-years of age and children having underlying heart disease or pulmonary tuberculosis presenting as pneumonia.

All the patients between two months to five years of age admitted to paediatric ward having cough or difficulty in breathing were examined and screened for features of severe and very severe pneumonia based on WHO diagnostic criteria. 5 . When chest in drawing is present along with fast breathing it is severe pneumonia and when cyanosis, severe chest in drawing, inability to feed is present along with fast breathing it is very severe pneumonia. Fast breathing was considered to be present when the respiratory rate was 50(Fifty) per minute or more for infants 2 months to 11 months of age and 40 (Forty) or above for children 12 months to 5years of age.

By simple consecutive sampling the sample size was taken to be 152 and all the children were registered and included in our study after informed consent was obtained from the parents or their legal heirs.

Proper history was taken regarding gestational age, immunization, feeding practice, exposure to tobacco smoke or to firewood, coal smoke and anthropometric measurements like height, weight were recorded in each case; which were then compared with the available norms of $50^{\text {th }}$ percentile of WHO standard. ${ }^{6}$ The grades of malnutrition were assessed as per weight-for-age 
criteria. ${ }^{7}$ Socioeconomic class was identified using Modified Kuppuswamy Scale. ${ }^{8}$

Everything was recorded in the case report format (CRF) specially designed for the study and follow up was done for 15 days or death whichever is earlier, during hospital stay only. After recording the data in the prescribed CRF, it was then transcribed in to SPSS data \& variable view. Data validation was done manually by two separate persons not involving in the present study. Statistical analysis was done with use of SPSS v 25. All continuous variable were analysed in terms of mean \pm SD for normally distribute data and median with IQR for non- normal data. Kaplan-meire survival curve was done to as sess the survival during hospitalization. T test was done to compare between two independent continuous variables.

\section{Results}

Table 2: Descriptive statistics of categorical variables

\begin{tabular}{|c|c|c|}
\hline Variables & Description of Variables & $\%(\mathrm{n})$ \\
\hline \multirow[t]{2}{*}{ Gender } & Male & $61.2(93)$ \\
\hline & Female & $38.8(59)$ \\
\hline \multirow[t]{2}{*}{ Weight as per gestational age } & AGA & $75(114)$ \\
\hline & SGA & $25(38)$ \\
\hline \multirow[t]{2}{*}{ Maturity } & Term & $80.9(123)$ \\
\hline & Preterm & $19.1(29)$ \\
\hline \multirow[t]{2}{*}{ Breastfeeding } & $\mathrm{EBF}$ & $59.2(90)$ \\
\hline & NEBF & $40.8(62)$ \\
\hline \multirow[t]{3}{*}{ PEM } & No Malnutrition & $4.6(07)$ \\
\hline & Moderate & $2.6(04)$ \\
\hline & Severe & $92.8(141)$ \\
\hline \multirow[t]{3}{*}{ Immunization Status } & Immunized as per NIS & $97.4(148)$ \\
\hline & Not immunized as per NIS & $2.6(04)$ \\
\hline & Extra Vaccine & $1.3(02)$ \\
\hline \multirow[t]{2}{*}{ Exposure to Smoke } & Exposed & $32.2(49)$ \\
\hline & Not exposed & $67.8(103)$ \\
\hline \multirow[t]{3}{*}{ SES } & Low & $35.5(54)$ \\
\hline & Middle & $58.6(89)$ \\
\hline & Upper & $5.9(9)$ \\
\hline \multirow[t]{2}{*}{ Severity of Pneumonia } & Severe Pneumonia & $59.2(90)$ \\
\hline & Very Severe Pneumonia & $40.8(62)$ \\
\hline \multirow[t]{2}{*}{ Outcome } & Discharge & $75.7(115)$ \\
\hline & Death & $24.3(37)$ \\
\hline
\end{tabular}

Median duration of survival in days of children with severe pneumonia $(8.0,6.60$ to 9.39$)$ is not significantly higher than the children with very severe pneumonia $(7.0,4.89$ to 9.10$)$ as evidenced by Breslow chi-square $=3.93$ (1), $\mathrm{p}=0.057$ (Fig. 2). There is no overall difference in survival among male and female as evidenced by Breslow chi-square $=0.314$ (1), $\mathrm{p}=$ 0.575. But among males the median duration of survival in days is significantly higher (7.0, 5.73 to 8.26) in severe pneumonia group as compared to very severe pneumonia $(6.0,3.19$ to 8.80$)$ as evidenced by Bres low chi-square $=4.42$ (1), p =0.035 (Fig. 3). There
Total 152 children included in our study out of which 37 children succumbed to death $(24.34 \%)$ whereas 115 children were successfully treated and discharged. The base line demographic data are given in the Table 1 and Table 2. Mean duration of Hospitalization in days of Very Severe Pneumonia $(8.02 \pm 6.56)$ is significantly lower than Severe Pneumonia $(10.08 \pm 7.05)$ as evidenced by $t$ $(150)=1.822, \mathrm{p}=0.0467$.

Table 1: Descriptive statistics of continuous variables

\begin{tabular}{|l|c|}
\hline \multicolumn{1}{|c|}{ Variables } & Median (IQR)* \\
\hline Age in months & $5(3-10)$ \\
\hline Weight in $\mathrm{Kg}$ & $5.350(4.0-7.70)$ \\
\hline $\begin{array}{l}\text { Duration of Hospitalis ation } \\
\text { in days }\end{array}$ & $8(4.25-12.0)$ \\
\hline
\end{tabular}

*IQR-Inter Quartile Range is no overall difference in survival among term and preterm as evidenced by Breslow chi-square $=0.064$ (1), $\mathrm{p}=0.800$. There is no overall difference in survival among three different socio economic group of children as evidenced by Breslow chi-square = 3.319 (2), $\mathrm{p}=$ 0.190 . There is overall no difference in survival among immunised children as compared to non-immunised as evidenced by Breslow chi-square $=4.043$ (1), $\mathrm{p}=0.054$ (Fig. 4). There is no overall difference in survival among exclusive breast fed babies as compared to bottle fed babies as evidenced by Breslow chi-square = 2.109 (1), $\mathrm{p}=0.146$. There is no overall difference in 
survival among babies exposed to s moke and those who were not as evidenced by Breslow chi-square $=1.287$ (1), $\mathrm{p}=0.257$.

Ethical Approval $\downarrow$

Enrolment of study participants satisfying Inclusion and Exclusion criteria $\downarrow$

In hospital follow up for 15days/Death (Whichever is earlier) $\downarrow$

Outcome analysed in terms of Survival analysis

Fig. 1:

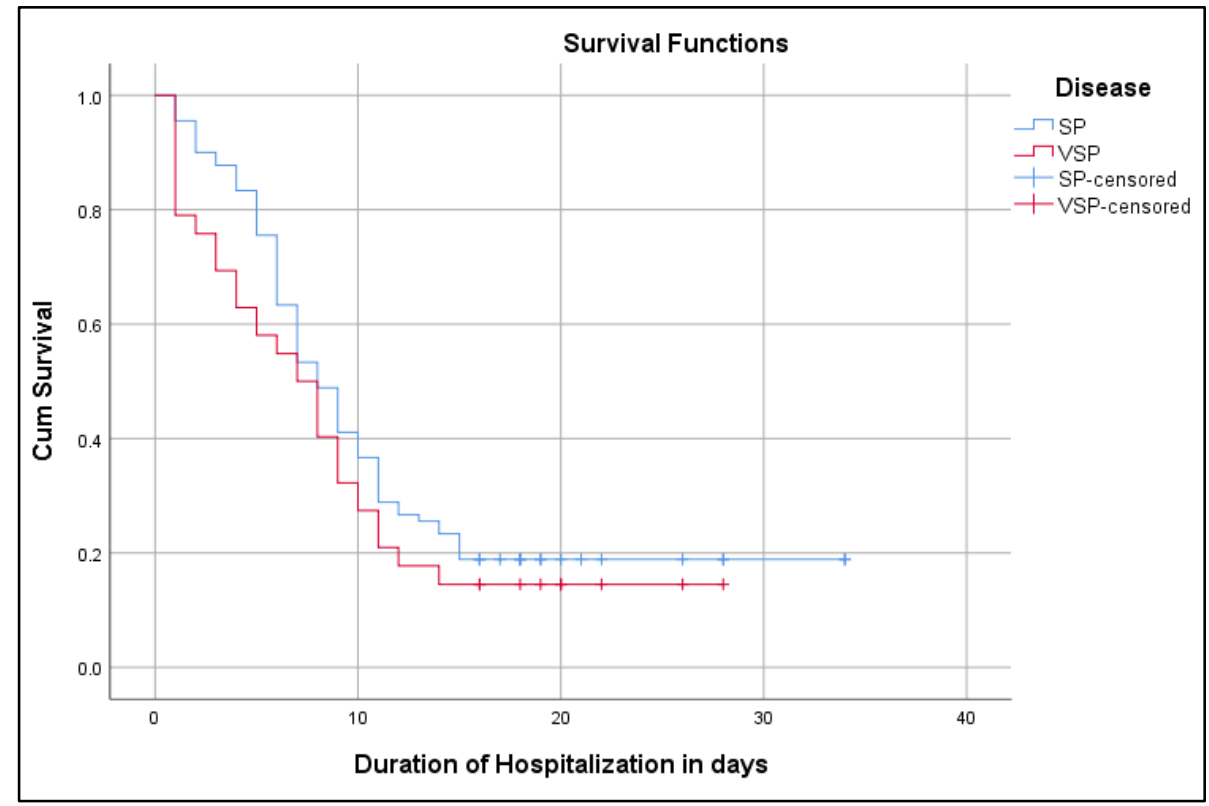

Fig. 2:

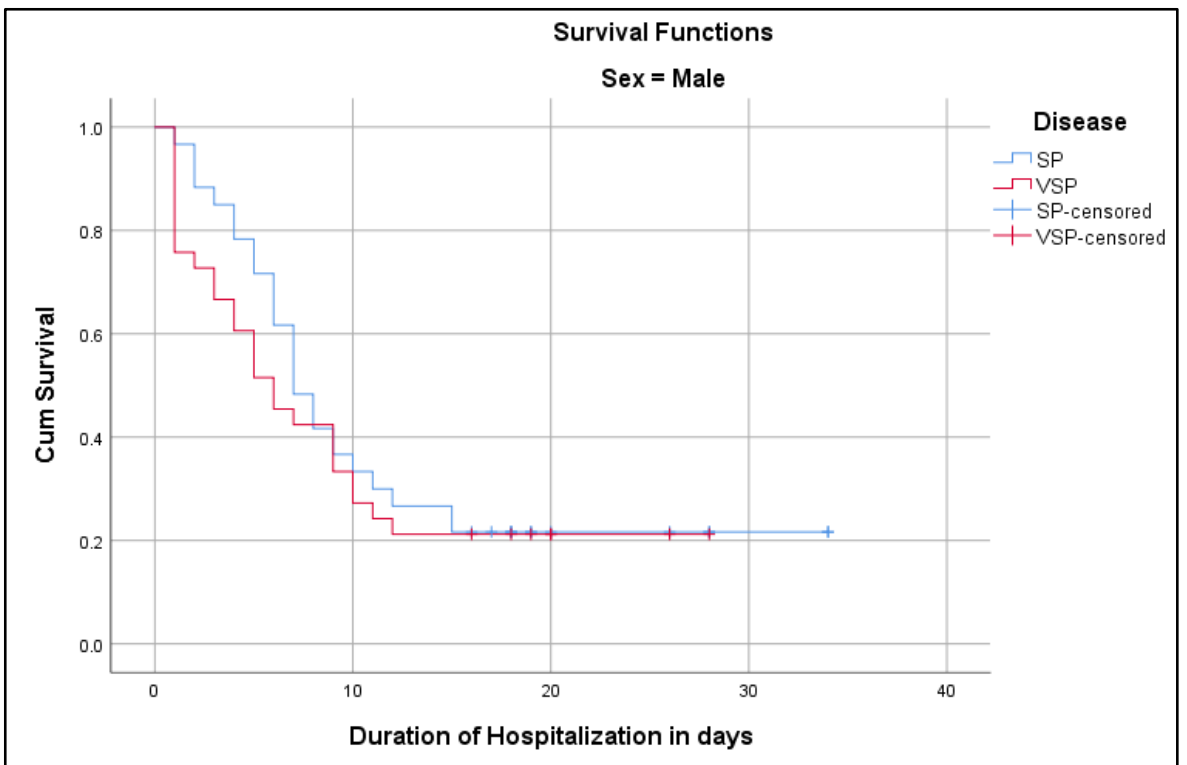

Fig. 3: 


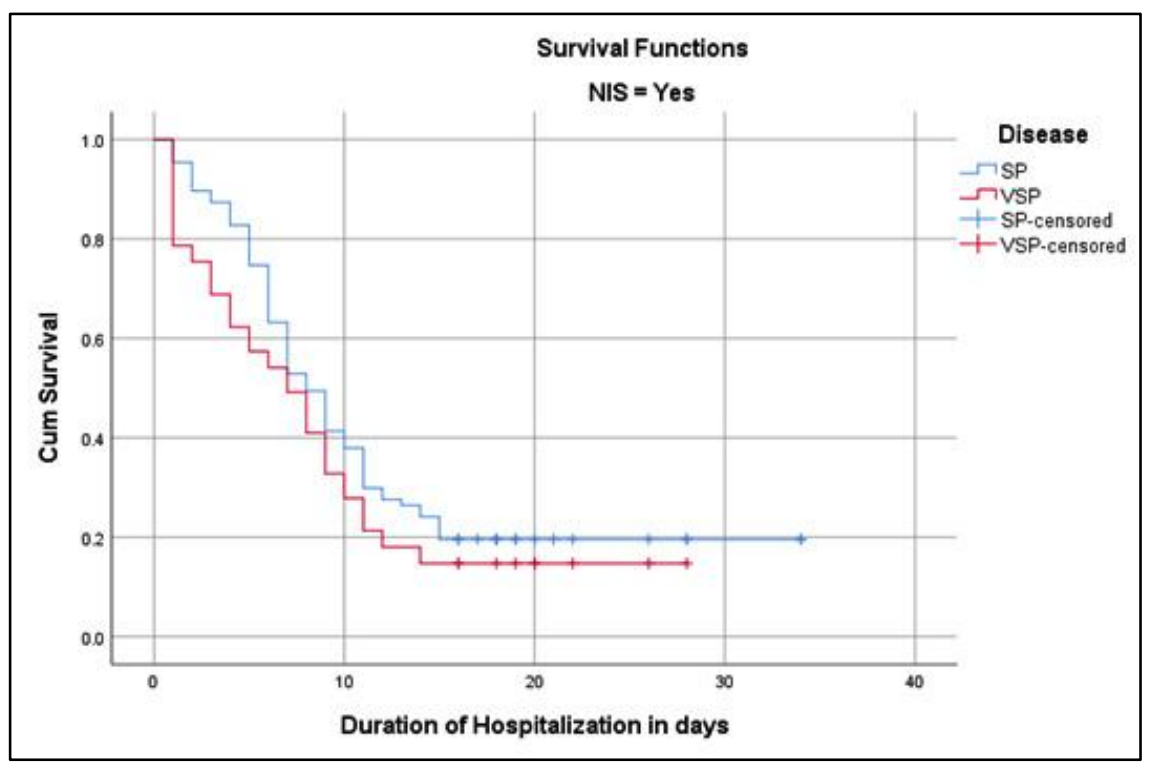

Fig. 4:

\section{Discussion}

In this study, we have analysed the clinical outcomes of children aged two months to five years who were admitted with signs and symptoms suggestive of severe and very severe pneumonia in a tertiary care health centre of western Odisha, India. We have compared the survivals of children amongst these two groups with specific reference to gender, gestational age, immunization and socio economic status.

Mortality of pneumonic children in our ICU set up is $24.34 \%$ which is in accordance with a study done in the year 2014 at eastern Odisha. ${ }^{9}$ But as per another study done at Karnataka in the year $2015^{10}$ observed mortality was $3 \%$. The higher mortality rate observed in our study could be due to less number of sample size in our study and late arrival to the hospital due to ignorance of the people of this region. In relation to a previous study ${ }^{11}$ the mortality was $3.6 \%$. This extremely low mortality rate as compare to our study may be explained by various geographical, ethnic, racial and health technology attributes. Small sample size of our study may be also a determinant for this outcome.

Our study pointed out the average duration of hospitalization in days was significantly less $(8.02 \pm 6.56)$ for very severe pneumonia as compared to severe Pneumonia (10.08 \pm 7.05$)$. According to a study done in eastern part of Odisha in the year 2015, average duration of hospital stay was $3.94 \pm 4.32$ days for nonsurvivor and $10.75 \pm 6.7$ for survivors. ${ }^{9}$ But this difference in result may be due to consideration of different categories of patients.

In our study median duration of survival before death is more or less same in severe and very severe pneumonic children which are approximately 7 to 8 days. This may be explained with the fact that disease severity merely affects the morbidity and mortality which may be due to late diagnosis and late referral. As per another study the average duration of hospital stay before death was 3.0 days. ${ }^{11}$ This discrepancies of results amongst various studies in comparison to our study may be due to the fact that all the reference studies $^{12-16}$ have done only basic statistical analysis except ourselves in which survival analysis has been done i.e., time to event analysis. Furthermore our study separated the study population in to two groups in contrast to other reference studies. ${ }^{13-18}$ But survival of male is more than female in case of severe pneumonia. This may be due to male predominant society of our region and male seeks early attention as compared to female. This result is supported by previous studies. ${ }^{15-18}$

There is no significant median duration of survival in days between term versus preterm children, exclusive versus nonexclusive breastfed children, immunized versus non immunized, exposed to smoke versus non exposed children and children of different socioeconomic groups. There are no such previous studies supporting our evidence. This result may be due to unequal distribution within the different groups which is ultimately due to the small sample size. This could have been avoided by paired case control s tudy.

The major limitation of this study is follow up period only during hospitalization, not beyond that. So survival of these patients could not be estimated properly. Again sample size could not be estimated statistically and we have taken patients by simple consecutive sampling, thus power of the study may be hampered. This is a hospitalbased study, so its outcome can't be applied to general population. So in future a larger multicentric study should be attempted based upon the outcome of the present study. 


\section{Conclusion}

Here in our study we found that though the mean duration of hospitalization in days significantly differs between severe and very severe pneumonia, but the disease survival (time to event analysis) merely affected by the disease severity which may be definitely affected by late referral and late in seeking medical facility. So the field health staffs to be trained properly and should be encouraged for early recognization of the disease condition and early referral, so that the severity of the disease can be prevented from progression. Hence the health technologies of our primary health centres should be strengthened enough to meet this need.

Author's Contributions: SCM has done the study design; BNK has done data collection, data validation and analysis. All the authors are responsible for designing of the manuscript and proof reading.

Acknowledgement: We would like to give our sincere solicitation to our beloved Dr S K Murmu (Professor \& HOD, Paediatrics) and at last but not the least the patients without whom this study could not have been possible.

\section{Conflict of Interest: Not stated}

\section{Funding: Self}

\section{References}

1. Thomas, K. Global burden of pneumonia. International Journal of Infectious Diseases, Volume 45, (Suppl. 1), April 2016.

2. Coverage Evaluation Survey, 2009. (UNICEF). [Cited 2015 March 11]; Available from http://unicef.in/

3. http://niti.gov.in/content/under-5-mortality-rate-u-5mr1000-live-births\#

4. Ramachandran, P., Nedunchelian, K., Vengatesan, A. et al. (2012) Risk factors for mortality in community acquired pneumonia among children aged 1-59 months admitted in a referral hospital. Indian Pediatr 49:889895.

5. World Health Organization. Pocket book of hospital care for children: guidelines for the management of common illnesses with limited resources. Geneva: The Organization;2005.

6. Khadilkar V, Khadilkar A. Growth charts: A diagnostic tool. Indian J Endocrinol Metab. 2011 Sep; 15(Suppl3): S166-S171. doi:10.4103/2230-8210.84854.

7. Physical Status: The Use and Interpretation of Anthropometry. WHO Technical Report Series 854. Report of a WHO Expert Committee. World Health Organization, Geneva, 1995.

8. Shaikh Z, Pathak R. Revised Kuppuswamy and B G Prasad socio-economic scales for 2016. Int J Community Med Public Health 2017;4:997-9.

9. Champatiray J, Satapathy JR, Kashyap B, Mondal D. Clinico-Aetiological Study of Severe and Very Severe Pneumonia in Two Months to Five Years Children in a Tertiary Health Care Centre in Odisha, India. Journal of Clinical and Diagnostic Research. 2017 Sep; 11(9): SC06-SC10. DOI: 10.7860/JCDR/2017/26027.10595.
10. Kumar AMK, Badakali AV, Mirji G, Vanaki RN, PolR. Clinical profile and outcome of acute lower respiratory tract infection in children aged between 2 months to 5 years. International Journal of Contemporary Pediatrics. 2017;4(1):105-09.

11. Nantanda R, Ostergaard MS, Ndeezi G, Tumwine JK. Clinical outcomes of children with acute asthma and pneumonia in Mulago hospital, Uganda: a prospective study. BMC Pediatrics. 2014;14:285.

12. Rudan I, O'Brien KL, Nair H, et al. Epidemiology and etiology of childhood pneumonia in 2010: estimates of incidence, severe morbidity, mortality, underlying risk factors and causative pathogens for 192 countries. $J$ Glob Health. 2013;3:10401.doi:10.7189/jogh.03.010101.

13. Roxburgh CS, Youngson GG, Townend JA, et al. Trends in pneumonia and empyema in Scottish children in the past 25 years. Arch Dis Child. 2008;93:316-318. doi:10.1136/adc.2007.126540.

14. Sazawal S, Black RE. Effect of pneumonia case management on mortality in neonates, infants, and preschool children: a meta-analysis of community-based trials. Lancet Infect Dis. 2003;3:547-556. doi:10.1016/S1473-3099(03)00737-0.

15. Walker CL, Rudan I, Liu L, Nair H, TheodoratouE, Bhutta ZA, et al. Global burden of childhood pneumonia and diarrhoea. Lancet. [Internet] 2013 [cited June 29, 2016];381(9875):1405-16. Available from: http:// www.thelancet.com /pdfs/journals /lancet/PIIS01406736(13)60222-6.pdf.

16. Crocker JC, Evans MR, Powell CV, Hood K, Butler CC. Why some children hospitalized for pneumonia do not consult with a general practitioner before the day of hospitalization. Eur J Gen Pract. [Internet] 2013 [cited June 29,2016];19(4):213-20. Available from: http:// www.tandfonline.com/doi/abs/10.3109/13814788.2013 .795538 ? journal Code=igen 20 .

17. Sonego M, Pellegrin MC, Becker G, Lazzerini M. Risk factors for mortality from acute lower respiratory infections (ALRI) in children under five years of age in low and middle income countries: a systematic review and metanalysis of observational studies. PloS one [Internet] 2015 [cited Jan 10, 2017]; 10(1):e0116380. Available from: http:// journals. plos.org/ plosone/ article? Id=10.1371/journal. pone. 0116380 .

18. Bhat, R. and Manjunath, N. (2013) Correlates of acute lower respiratory tract infections in children under 5 years of age in India. Int J Tuberc Lung Dis 17:418-422. 